\title{
APLICAÇõES INTERATIVAS COMO POTENCIALIZADORAS DE MÚLTIPLAS INTELIGÊNCIAS
}

\author{
INTERACTIVE APPLICATIONS AS MULTIPLE ENHANCING INTELLIGENCES \\ APLICACIONES INTERACTIVAS COMO POTENCIADOR \\ DE LAS INTELIGENCIAS MÚLTIPLES
}
LAS APLICACIONES INTERACTIVAS CÓMO POTENCIADORA
DE INTELIGENCIAS MÚLTIPLES

\section{Raquel Alves Santos ${ }^{1}$ \\ Edna Gusmão de Góes Brennand ${ }^{2}$ \\ Ismênia Mangueira Soares ${ }^{3}$}

\begin{abstract}
RESUMO
Esta pesquisa tem como objetivo a construção de um modelo conceitual para produção de conteúdos digitais ancorados na Teoria das Inteligências Múltiplas de Gardner - TIM. Este modelo fundamentou a produção do protótipo de material didático hipermídia com aplicação para a Televisão Digital Interativa - TVDI e potencial para ativar as cinco mentes definidas por Gardner (2007) como as necessárias aos gestores do futuro. O uso da ferramenta de autoria denominada MARKER validou o modelo conceitual e comprovou que ele possui boa aplicabilidade, visto que as aplicações interativas produzidas podem possibilitar aos gestores acionar suas múltiplas inteligências e buscar diferentes caminhos para a aprendizagem. A associação de recursos como a TVDI e conteúdos educativos interativos na educação propicia o surgimento de uma ferramenta midiática capaz de alavancar a construção de uma educação pautada em estratégias que lancem mão de técnicas e práticas que podem favorecer a aquisição do conhecimento.
\end{abstract}

PALAVRAS-CHAVE: Televisão digital interativa. Teoria das inteligências múltiplas. Aplicações interativas.

\section{ABSTRACT}

This research aims to build a conceptual model to the production of digital content based on the Theory of Multiple Intelligences Gardner - TIM. This model is related to the production of teaching materials with prototype hypermedia application for Interactive Digital Television - iDTV with potential to activate five minds that will be necessary to the future managers. The usage of an authoring tool called MARKER validated the conceptual model and proved that it has good applicability, since the produced interactive applications may enable managers to operate their multiple intelligences and search different paths for learning. The association resources such as iDTV and interactive educational content in education fosters the emergence of a media tool able to leverage the construction of guided education strategies that produce techniques and practices that can

\footnotetext{
${ }^{1}$ Mestre em Gestão em Organizações Aprendentes pela Universidade Federal da Paraíba, UFPB, João Pessoa, PB - Brasil. Pesquisadora da Universidade Federal da Paraíba, UFPB, João Pessoa, PB - Brasil.

E-mail: raca_alves@ hotmail.com.

${ }^{2}$ Doutora em Sociologia pela Universidade Paris I Pantheón Sorbonne, França. Professora Associada do Centro de Educação da Universidade Federal da Paraíba, UFPB, João Pessoa, PB - Brasil.

E-mail: ebrenna2@uol.com.br.

${ }^{3}$ Doutora em Educação pela Universidade Federal da Paraíba, UFPB, João Pessoa, PB - Brasil. Professora do Ensino Técnico e Tecnológico pela Universidade Federal da Paraíba, UFPB, João Pessoa, PB - Brasil.

E-mail: ismamangueira@gmail.com.

Recebido em: 18/05/2015 - Aceito em: 21/03/2016.
} 
promote the acquisition of knowledge.

KEYWORDS: Interactive digital television. Theory of multiple intelligences. Interactive applications.

\section{RESUMEN}

Esta investigación tiene como objetivo construir un modelo conceptual para la producción de contenidos digitales anclado en la Teoría de las Inteligencias Múltiples de Gardner - TIM. Este modelo basa la producción de materiales de enseñanza con prototipo de aplicación hipermedia para la Televisión Digital Interactiva - iDTV y el potencial para activar las cinco mentes que serán necesarios para los futuros directivos. El uso de la herramienta de autoría de MARKER llamada validó el modelo conceptual y demostró que tiene buena aplicabilidad, ya que las aplicaciones interactivas producidas pueden permitir a los administradores para operar sus inteligencias múltiples y buscar diferentes caminos para el aprendizaje. Las características de la asociación como iDTV y contenido educativo interactivo en la educación fomenta la aparición de una herramienta de comunicación capaz de aprovechar la construcción de unas estrategias educativas guiadas que se apoderan de las técnicas y prácticas que puedan fomentar la adquisición de conocimientos.

PALABRAS CLAVE: Televisión digital interactiva. Teoría de las inteligencias múltiples. Las aplicaciones interactivas.

\section{INTRODUÇÃO}

Este relato de experiência contém resultados relativos à investigação acerca da construção de um modelo conceitual para produção de conteúdos educativos interativos a serem veiculados através da Televisão Digital Interativa- TVDI e faz parte de uma pesquisa de mestrado que foi desenvolvida no âmbito do Grupo de Pesquisa Cultura Digital e Educação da Universidade Federal da Paraíba (UFPB). Apresenta a análise do processo de construção do modelo conceitual para produção dos conteúdos interativos. Este processo envolveu a metodologia experimental na produção do protótipo interativo em mídia impressa e audiovisual com a contribuição de uma equipe interdisciplinar composta pelas áreas de ciência da computação, comunicação e de educação. Para isso, o ciclo de construção desse protótipo foi fundamentado em diagnóstico de dados empíricos sobre o processo atual de formação de gestores técnico-administrativos da Universidade Federal do Rio Grande do Norte (UFRN), pressupostos teórico-conceituais levantados na pesquisa e o uso da ferramenta de autoria denominada MARKER, cuja funcionalidade foi gerar aplicações interativas para TVDI baseadas em técnicas de marcação em vídeo, num contexto que possibilitou a interação com outros conteúdos como textos, imagens, simulações, animações, entre outros, despertando a atenção do aprendente sobre o assunto estudado.

Desta forma, o diagnóstico realizado na UFRN permitiu a determinação do cenário atual do processo de formação existente, definiu o perfil do gestor, o tipo de conhecimento (tácito, explícito), as competências a serem desenvolvidas, e forneceu subsídios para a criação do modelo conceitual que fundamentou a construção do protótipo de material didático hipermídia para educação a distância de gestores com foco na TIM e nas cinco mentes, que Gardner (2007) define como mais valiosas no futuro: disciplinada, sintetizadora, criadora, ética e respeitosa. 
Como suporte para essa discussão, trouxemos a Teoria das Inteligências Múltiplas de Gardner (2000), que ancorou a construção do modelo conceitual possibilitando a produção de dois materiais: um caderno didático e uma videoaula interativa, a serem utilizados na formação gerencial por meio da educação a distância (EAD), e com potencial para ativar as cinco mentes mais necessárias aos gestores do futuro, dentro de uma perspectiva em que cada pessoa tem a sua individualidade, e, ao aprender, podem ativar uma combinação única de inteligências.

Gardner (2007) retrata ainda a necessidade de cultivar cinco mentes para o futuro e define as melhores formas de fazê-lo, não pretendendo delinear capacidades perceptivas e cognitivas específicas que sustentam as mentes. Para ele, "as cinco mentes são diferentes das onze inteligências humanas. Em lugar de distintas capacidades, elas são concebidas como usos amplos da mente que podem ser cultivados na escola, nas profissões ou no local de trabalho" (GARDNER, 2007, p. 13).

Além da sustentação nas teorias, segundo Brennnand e Lemos (2007), as tecnologias, que permitem mais e mais interação, trarão em si as possibilidades de ampliação dos processos cognitivos. Assim, a produção desses materiais interativos torna-se, então, uma tecnologia educativa, em que procedimentos didáticos e pedagógicos poderão gerar uma aprendizagem mais dinâmica e flexível.

Desta forma, o estudo permitiu o processo de criação de um protótipo balizado na necessidade de construção de um modelo inovador para a formação de gestores, que contemplasse a modalidade de educação à distância e os materiais com conteúdos não lineares, conjugados com tecnologias digitais e ações pedagógicas, representando uma alternativa para a democratização do ensino e o crescimento das oportunidades de aprender.

Face ao exposto, apresentamos, assim, os primeiros resultados advindos da aplicação de mídias tecnológicas na educação de gestores, com aplicação de uma pedagogia que multiplica ou torna diferente as formas como o conteúdo pedagógico se apresenta, a exemplo da TVDI, ou seja, dos conteúdos interativos gerados a partir do modelo conceitual concebido e da ferramenta MARKER, apontando os conteúdos produzidos como potencializadores das múltiplas inteligências nos aprendentes.

\section{CONSTRUÇÃO DO MODELO CONCEITUAL}

De acordo com Gardner (2000), um conteúdo educativo interativo, ao oferecer diferentes rotas de acesso ao conhecimento para os seus aprendentes, que tenha como proposta o ensino para a compreensão, estará proporcionando um caminho para o entendimento de um determinado assunto, mobilizando um conjunto de inteligências diferentes. Nesse sentido, cada indivíduo tem habilidades distintas e isso determina a diferença entre eles, visto que cada indivíduo aprende do seu modo pessoal e único. Para 
aprender, Soares (2014) coloca que é preciso percorrer diferentes abordagens ou caminhos que cada um pode traçar para si mesmo.

Dentro desse contexto, o processo de conhecer pode ser enriquecido quando temos acesso a conteúdos concebidos, a partir de um modelo que, para Soares et al. (2013), envolve a tríade "educação-tecnologia-cognição". Nas últimas duas décadas, os modelos teóricos que possibilitam integração entre plataformas tecnológicas e ações pedagógicas abrem espaços para novas reflexões no campo educacional.

Nesse cenário, a hipermídia constitui-se uma excelente ferramenta na construção do conhecimento devido a dois motivos básicos, a saber: a possibilidade de interação por parte do usuário e a união das diversas mídias existentes. A esse respeito, a utilização do hipertexto em união com a multimídia traz os recursos necessários para auxiliar no desenvolvimento das várias inteligências do indivíduo, uma vez que a interação proporcionada pelo hipertexto respeita as características individuais e as várias mídias disponibilizadas falam aos diferentes canais de percepção que cada um possui.

Segundo Paim (2006), a hipermídia surgiu a partir do desenvolvimento do hipertexto integrado à multimídia, que se tornaram realidade com a evolução das interfaces gráficas, permitindo apresentar ao usuário uma diversidade de mídias como imagens, textos, animações e sons. A partir da inclusão das ferramentas de interação, a hipermídia passou a oferecer diferentes modos de navegação, contribuindo para que essa navegação tenha um formato não linear, proporcionando ao aprendente mais liberdade de escolha dentro do ambiente.

Ademais, um conteúdo hipermídia pode contribuir para a quebra do paradigma do pensamento linear para um novo paradigma: o pensamento hipertextual.

Segundo Pierre Lévy (1996), um hipertexto é um conjunto de nós ligados por conexões. Esses nós podem ser palavras, páginas, imagens, gráficos, sequências sonoras, documentos complexos, os chamados documentos hipermídia.

Os documentos hipermídia desembocam na construção de um novo espaço, de base virtual, denominado de ciberespaço, no qual, de acordo com Lévy (1996), o saber articula-se à nova perspectiva de educação, conforme retratado na figura 1, em função das novas formas de se construir conhecimento, que contemplam a democratização do acesso à informação, os novos estilos de aprendizagem e a emergência da inteligência coletiva. 


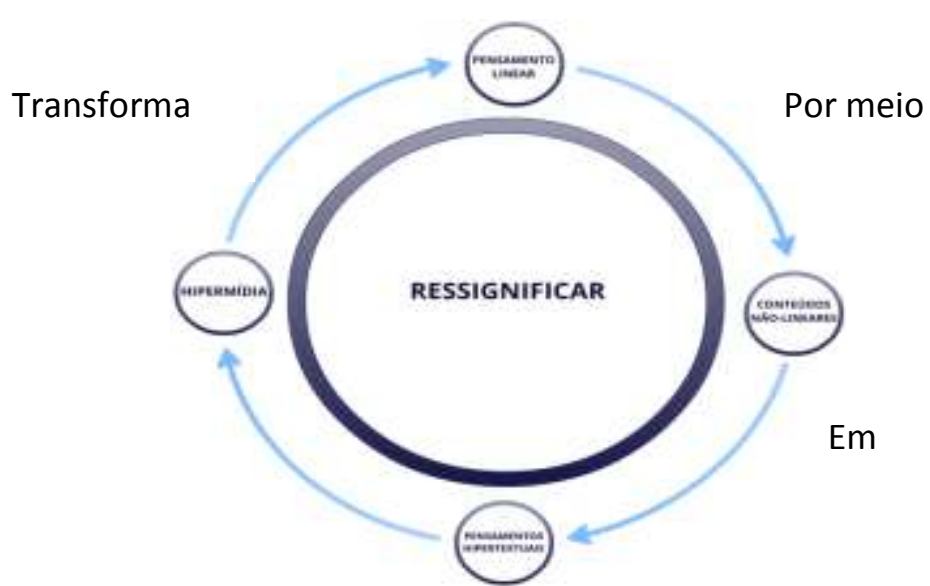

FIGURA 1- Nova perspectiva para Educação Fonte: Autoria própria (baseado em LÉVY, 1996)

Para aprimorar o uso das diferentes mídias em EaD, faz-se necessário o conhecimento dos seus aspectos técnicos e didáticos, sua aplicabilidade, alcance e integração, buscando a elaboração de estratégias específicas para otimizar sua utilização, como afirma Neder (2001). No âmbito educacional, as pesquisas e o desenvolvimento de ferramentas digitais com o uso de hipermídias têm recebido grande impulso, principalmente com o crescimento dos cursos na modalidade distância (PALAZZO, 2002).

Considerando que a mediação da relação professor/aluno e do processo de aprendizagem na EaD passa pela interação com as mídias disponíveis, ela deve ser vista e entendida na perspectiva da tecnologia educacional como um meio e não um fim, seja por um canal ${ }^{4}$ síncrono seja por um assíncrono, com um grau maior ou menor de interatividade. No contexto atual da $\mathrm{EaD}$, muitos modelos voltam-se para a utilização de mídias digitais. Nesse cenário, as TIC e o material didático hipermídia possibilitam a operação simultânea com textos, imagens, vídeos e sons, que podem ser modificados, reorganizados com a desejável interação.

Essas tecnologias, para Gardner (2001), podem promover um "salto quântico" na prestação de serviços individualizados para alunos e professores, enfatizando principalmente a utilização do correio eletrônico, websites, videoconferências, entre outras ferramentas utilizadas amplamente no ensino à distância. O autor considera ainda a importância do desenvolvimento de "sistemas inteligentes", definindo que "esses sistemas devem ser capazes de permitir variar tanto os exercícios quanto o retorno pedagógico baseado no êxito ou nos fracassos anteriores". "[...] As tecnologias correntes parecem feitas, sob medida, para tornar real o tipo de abordagem das inteligências múltiplas” (GARDNER, 2001, p. 218).

\footnotetext{
4 “Ao contrário do ensino presencial, o ensino on-line é uma nova abordagem pedagógica, pois é um sistema de ensino-aprendizagem, síncrono (simultâneo) ou assíncrono (não simultâneo) (MOORE; KEARSLEY, 2007, p. 63)".
} 
Modernamente, não se podem ignorar os programas computacionais e conteúdos educativos voltados para ativar as múltiplas inteligências, permitindo ao aprendente desenvolver diferentes formas de conhecer, demonstrando sua compreensão em vários sistemas de símbolos, sendo eles linguísticos, numéricos, musicais ou gráficos.

Segundo Soares et al. (2013), as ferramentas de interação, potencializadas com o uso da hipermídia, tornam o espaço virtual fecundo de possibilidades para a educação quando integra pessoas, plataformas tecnológicas e conteúdos pedagógicos. Assim, os diferentes tipos de inteligências podem ser acionados a partir do uso de várias mídias cujo potencial venha favorecer a ancoragem de novas informações e conhecimentos.

Um material educativo interativo na EaD que ative as múltiplas inteligências de um aprendente requer como critérios para a sua produção os seguintes fatores: definição de público-alvo, escolha do tema e conteúdos, roteiro a ser seguido, competências a ser desenvolvidas, linguagem a ser utilizada, mídias a ser usadas, proposta teórico-metodológica e outros recursos tecnológicos.

Nessa perspectiva, a produção do material didático exige um repensar pedagógico, incluindo a criação de estratégias didático-pedagógicas para uma efetiva aprendizagem em uma nova configuração, em que a mídia e as TIM devem ser utilizadas como apoio a um processo planejado. Uma vez estabelecidos esses critérios, definimos que a construção do protótipo de material didático hipermídia, com base na TIM, deveria obedecer às etapas propostas pelo modelo conceitual encontrado na tese de Soares (2014). Para ela, construir um modelo conceitual ancorado na Teoria das Inteligências Múltiplas de Gardner (2000), em que a capacidade de ressignificar conteúdos permita a criação de contextos atrativos aos aprendentes, abordando situações que apontem os caminhos adequados à aprendizagem foi um grande desafio.

Além disso, o ponto de partida desse modelo foi considerar que cada indivíduo tem habilidades diferentes e refletir sobre a seguinte questão: de que forma poderíamos encontrar subsídios que viessem propiciar a construção de um modelo conceitual que ancorasse a possibilidade do uso de estratégias de ensino-aprendizagem com vistas a uma nova visão de educação? Fundamentada nessa indagação, Soares (2014) encontrou a contribuição das ciências cognitivas que permitiu pensar modelos em que os indivíduos, ao trabalhar com conteúdos educativos, pudessem potencializar determinadas inteligências, e, como elas estão interligadas, permitiu alcançar um melhor nível de competência na sua aprendizagem. Esse cenário é intrínseco à compreensão de aprendizagem apresentado por Gardner (2000) em sua teoria.

O modelo foi pensado com base na participação ativa do aprendente, na exploração e na experimentação quando das escolhas feitas durante o percurso de navegação do conteúdo interativo (SOARES, 2014). Assim, desenvolvemos um material didático hipermídia para a formação gerencial que pudesse validar o modelo para a criação de conteúdos interativos, 
oportunizando ao aprendente estabelecer conexões com outros conteúdos que considere essencial a sua aprendizagem.

Em observância ao estabelecido, partimos do pressuposto de que um ambiente educacional deve promover ao aprendente um contexto em que ele possa vivenciar a velocidade com que as transformações tecnológicas e científicas acontecem, fazer uso dos produtos advindos dessas transformações na geração de novos conhecimentos e de ferramentas inovadoras que permitam realimentar esse processo, contribuindo para o desenvolvimento de novas competências.

Face ao exposto, o modelo conceitual apresentado na figura 2 foi baseado no esquema de modelagem matemática proposto por Bassanezi (2002, p. 27) e segundo Soares (2014).

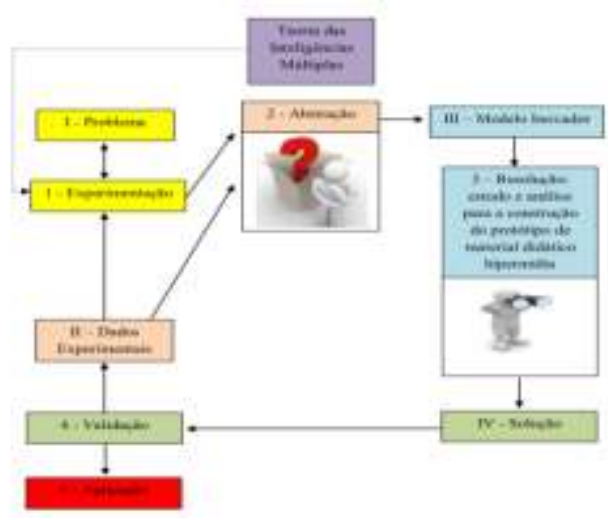

FIGURA 2 - Modelo Conceitual

Fonte: Baseada em Bassanezi (2002) e Soares (2014)

Legenda: retângulos com algarismos romanos estão no nível correspondente aos retângulos com algarismos arábicos. A seta pontilhada partindo da TIM (GARDNER, 2000) para o item 1 indica que a fase da experimentação foi ancorada pelos pressupostos dessa teoria. A seta bidirecional demonstra que é possível voltar à fase anterior. As setas numa única direção indicam o fluxo que deve ser percorrido para a construção do protótipo de material didático hipermídia. $\mathrm{O}$ retângulo com o algarismo arábico 5 representa a construção do protótipo de material didático hipermídia com a utilização da ferramenta MARKER para aplicação interativa validada à luz da Teoria de Gardner (2000).

Segundo Bassanezi (2002), a modelagem matemática é uma forma de abstração e generalização com a finalidade de previsão de tendências que consiste, essencialmente, na transformação da realidade em problemas matemáticos cujas soluções devem ser interpretadas na linguagem usual. O autor destaca que é importante a conscientização de que a modelagem é um trabalho de aproximação da realidade e que nenhum modelo deve ser considerado definitivo, podendo ser sempre melhorado. Diante desse entendimento, apresentaremos as etapas que esse modelo conceitual contempla para a construção do protótipo de material didático hipermídia a ser utilizado na educação a distância de gestores: 
- $\quad$ Experimentação: é uma atividade essencialmente laborativa em que se processa a obtenção de dados para dar conta do problema não matemático.

- Abstração: é o momento de selecionar as variáveis, formular questões, levantar hipóteses.

- Resolução: quando acontece a troca da linguagem natural das hipóteses pela linguagem matemática coerente.

- $\quad$ Validação: é o processo de aceitação ou não do modelo proposto.

- Modificação: alguns fatores ligados ao problema original podem provocar rejeição ou aceitação do modelo.

\section{DEFINIÇÃO DAS CATEGORIAS BASILARES DA TIM PARA CONSTRUÇÃO DO MODELO CONCEITUAL}

Por se tratar de um modelo que visa favorecer a aprendizagem humana, mediante a produção de conteúdos interativos, buscamos na teoria das inteligências múltiplas os pressupostos que embasam uma teoria da aprendizagem, extraindo conteúdos que, associados aos recursos tecnológicos utilizados, pudessem favorecer a ativação das múltiplas inteligências nos aprendentes.

O modelo permitiu construir um protótipo de material didático hipermídia a ser utilizado na educação à distância de gestores, cujos pressupostos investigados dizem respeito às categorias basilares da TIM. A partir do modelo, foi planejado o material didático interativo em forma de caderno didático tendo como complemento uma videoaula, envolvendo diversos hiperlinks como o vídeo, áudio, imagens, textos, tendo a TV Digital como suporte. Para o uso dos processos interativos, colocamos à disposição do aprendente diversos tutoriais, de forma que, passo a passo, ele possa acessar outros materiais de apoio.

Para estabelecer a associação pretendida entre os conteúdos disponibilizados, foram adotados como critério os ícones representativos das inteligências múltiplas consolidados por Zandomeneghi (2005), conforme apresentado na Figura 3. Considerando o resultado do diagnóstico de dados empíricos sobre o processo atual de formação de gestores da UFRN, estes critérios nos fizeram escolher como categorias basilares as inteligências musical, corporal cinestésico, lógico-matemática, espacial, intrapessoal, interpessoal e linguística, pois seriam as mais significativas para o desempenho dos gestores em tarefas administrativas nas organizações. 


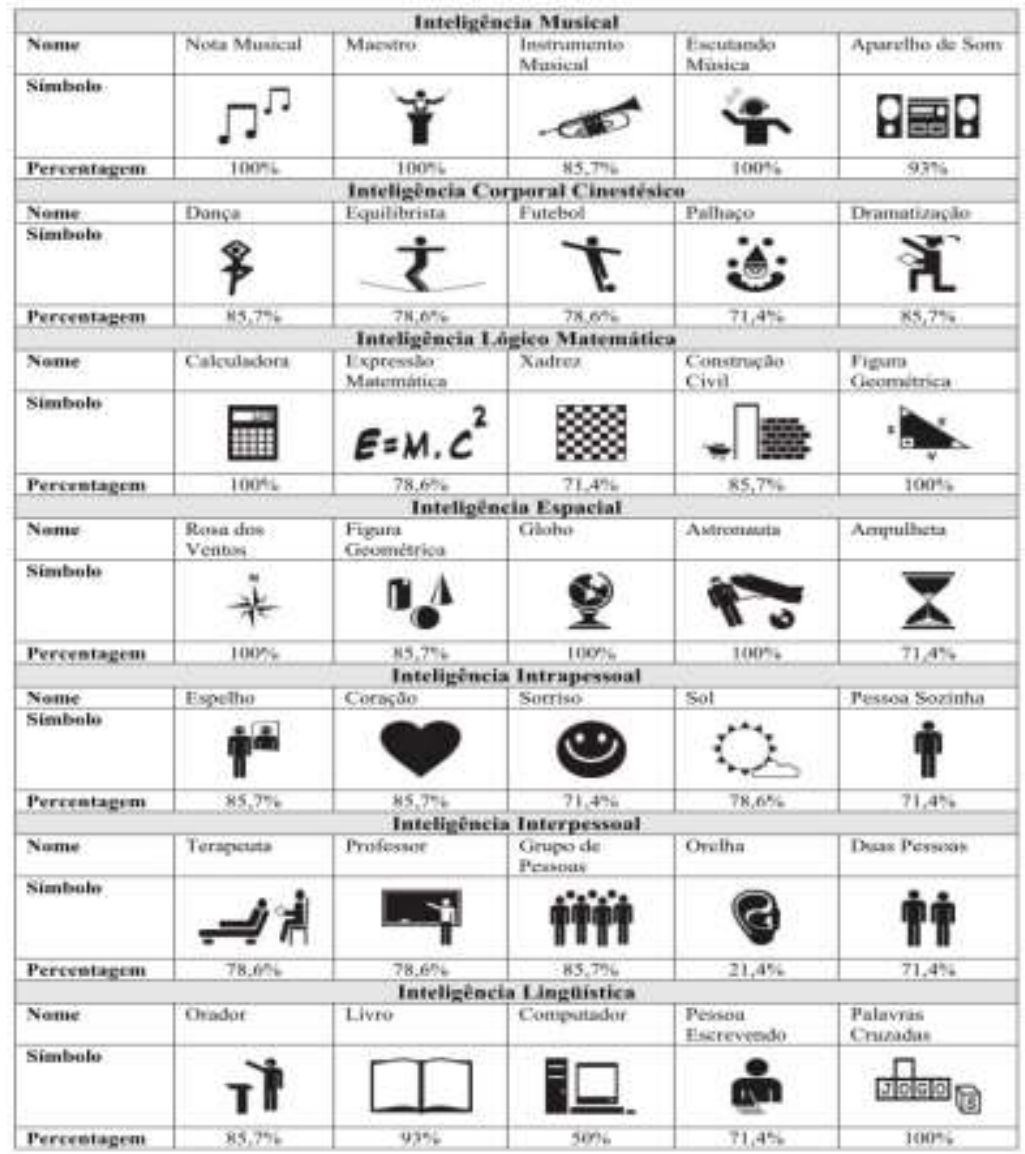

FIGURA 3 - Ícones representativos das Inteligências Múltiplas Fonte: Zandomeneghi (2005)

Para Gardner (2000), todos os indivíduos são capazes de uma atuação em diferentes habilidades, independentemente das áreas intelectuais. Explica que apenas diversas inteligências funcionando em combinação é que são necessárias para esclarecer como os seres humanos assumem papéis diversos, como professores, médicos, engenheiros ou músicos. Resulta, portanto, dessa concepção o cerne da teoria de Gardner, uma vez que, para ele, não existe somente uma capacidade mental implícita e sim a manifestação de diversas inteligências funcionando, em combinação. Sob essa ótica, o desenvolvimento de determinada inteligência, bem como a combinação delas, não impossibilita a aquisição ou potencialização de outras inteligências, assim, qualquer indivíduo pode atingir um grau adequado de habilidades, desde que possua condições apropriadas e oportunas. Buscamos, então, trabalhar cada inteligência a partir do que o autor considera como capacidade que o ser humano dispõe para resolver problemas. Assim, ao navegar por um conteúdo interativo, o aprendente estaria sendo alcançado pelo professor de uma forma mais direta e específica. 
Além disso, Gardner (2007, p. 14) define ainda as cinco mentes "como as capacidades cognitivas que serão mais valiosas e procuradas no futuro e afirma que elas fazem uso de nossas várias inteligências", afirmando, como exemplo, que cultivar o respeito seria impossível, sem o exercício da inteligência interpessoal. De acordo com esse autor, as mentes podem ser alteradas quando um novo conteúdo é apresentado em uma série de diferentes meios e símbolos. Assim, ao explicar as mentes, Gardner (2007) comenta como elas tomam forma em outras carreiras, principalmente nos negócios e nas profissões com formação superior.

Em decorrência do exposto, todas as mentes são necessárias, priorizadas e valorizadas na sociedade contemporânea e na sociedade do futuro, porém, para Gardner (2007), a respeitosa e a ética são as mais importantes. Sob essa ótica, ele destaca que a disciplinada é a base e, quando unida às mentes sintetizadora e criadora de natureza cognitiva, formam uma sequência lógica, ou seja, cada uma delas constrói a sucessiva. Já as outras duas - respeitosa e ética - estão pautadas nas relações humanas.

\section{ADEQUAÇÃO DAS CATEGORIAS À CONSTRUÇÃo DO PROTÓTIPO DA FERRAMENTA}

A adequação de passos para a construção do protótipo desse material didático aos pressupostos investigados exigiu que compreendêssemos melhor, do ponto de vista técnico, como iríamos despertar a atenção do aprendente para conteúdos específicos, fazendo uso de seu potencial cognitivo. Nessa perspectiva, tornou-se um desafio à construção de um material que integre, dentro de um modelo de processo de formação gerencial, a hipermídia, a TVDI e a TIM para o desenvolvimento de conteúdos educativos interativos com potencial para ativar as inteligências humanas e as mentes julgadas essenciais aos profissionais do século XXI. As aplicações utilizadas foram criadas com base na Teoria das Inteligências Múltiplas (TIM), com foco na inserção de conteúdos a partir de um vídeo base e desenvolvidas na linguagem Nested Context Language (NCL). E, uma vez que são executadas no ambiente Ginga-NCL, tornam esse processo mais ágil, rápido e incremental, além de ser uma linguagem de fácil assimilação, semelhante às outras linguagens de marcação bastante conhecidas como XML (Xtensible Markup Language) e HTML (HyperText Markup Language). Por sua vez, o ambiente de apresentação multimídia Ginga-NCL nos forneceu meios para execução de aplicações, com âncoras hipermídia na linguagem NCL para TV Digital, no momento de seu desenvolvimento pela ferramenta MARKER, sendo, assim, possível verificar o estado atual da aplicação no instante de sua implementação.

Considerando o estabelecido, o uso da ferramenta MARKER validou o modelo conceitual e comprovou que ele possui boa aplicabilidade, visto que as aplicações interativas produzidas podem possibilitar aos gestores acionar suas múltiplas inteligências e buscar diferentes caminhos para a aprendizagem. Ademais, a validação do modelo permitiu verificar que a interatividade proporcionada pelo material pode conduzir o aprendente a desenvolver potencialidades para ativar as mentes mais valorizadas no futuro. 
Desse modo, a ferramenta MARKER favoreceu a aprendizagem humana por meio da produção de conteúdos interativos embasados na Teoria das Inteligências Múltiplas, permitindo um novo significado a conteúdos que, associados aos recursos tecnológicos utilizados, permitissem a ativação das múltiplas inteligências nos aprendentes.

\section{A CONSTRUÇÃO DO PROTÓTIPO BASEADO NO MODELO}

Pensar um protótipo em que o gestor pudesse trabalhar e aprender de forma colaborativa, com base em sua participação ativa na exploração e na experimentação quando das escolhas feitas durante o percurso de navegação de um conteúdo interativo tornou-se essencial. Dessa maneira, produzimos um protótipo de material didático hipermídia utilizando a ferramenta MARKER que, segundo Soares (2014), oportuniza ao aprendente estabelecer conexões com outros conteúdos que considere essenciais à aprendizagem, de forma que sejam estimulados a navegar de acordo com suas habilidades.

Dessa forma, a produção do protótipo com o uso dessa ferramenta de autoria possibilitou a validação do modelo para a criação de conteúdos interativos, com base em Bassanezi (2002) e Soares (2014), conforme apresentado na figura 2; permitindo, assim, a criação de um protótipo inovador na educação de gestores, com aplicação de uma pedagogia que multiplica ou torna diferente as formas como o conteúdo pedagógico apresenta-se, a exemplo da TVDI.

Diante dessas concepções, ao propormos a produção do protótipo de material didático hipermídia para a educação à distância, consideramos primordial, conforme coloca Belloni (2008), conceber metodologias de ensino e estratégias de utilização de materiais de ensino/aprendizagem que potencializem ao máximo as possibilidades de aprendizagem autônoma. Isso inclui a seleção e elaboração de conteúdos; a criação de metodologias de ensino e de estudo, centradas no aprendente, voltadas para a formação da autonomia; a seleção dos meios mais adequados; a produção de materiais; e até a criação de estratégias de utilização de materiais de modo a assegurar a interação do estudante com o sistema de ensino.

No material didático hipermídia, composto pelo caderno didático complementado por uma videoaula, considerando o mapeamento das competências, estabelecemos a possibilidade de uso de sete inteligências mais significativas para o desempenho dos gestores em tarefas administrativas nas organizações, como já dito, sendo elas: linguística, lógico-matemática, musical, espacial, corporal-cinestésica, intrapessoal e interpessoal, com potencial para ativar cinco mentes: disciplinada, sintetizadora, criadora, ética e respeitosa.

Uma vez realizada as referidas definições, o professor conteudista desenvolveu, num período de sessenta dias, um conteúdo inovador voltado para a formação gerencial, com potencial para promover um conjunto de inteligências e acionar as cinco mentes mais valorizadas no futuro. 
Finalizada essa fase, iniciamos a inserção de interatividade no material didático hipermídia. Por se tratar de um projeto técnico aplicado, os recursos interativos foram definidos pela pesquisadora e, em reunião técnica realizada com o professor conteudista, eles foram validados. Ou melhor, ratificamos o conteúdo das mídias que utilizaríamos para que o gestor pudesse buscar conhecimentos em outros contextos e quais ícones representativos das múltiplas inteligências seriam mais pertinentes para cada conteúdo adotado. Realizamos essas definições com base em análises à luz da TIM e do que Gardner (2007) define sobre as cinco mentes para o futuro.

$\mathrm{Na}$ produção do caderno didático, composto por uma aula, utilizamos os critérios estabelecidos pela ferramenta MARKER para realizar o percurso do fazer pedagógico, disponibilizando todos os hiperlinks durante o texto, por meio do uso dos ícones representativos das inteligências múltiplas e mídias desacopladas (QR CODE), tornando-o uma ferrmenta interativa de comunicação digital, de acordo com a figura 4:

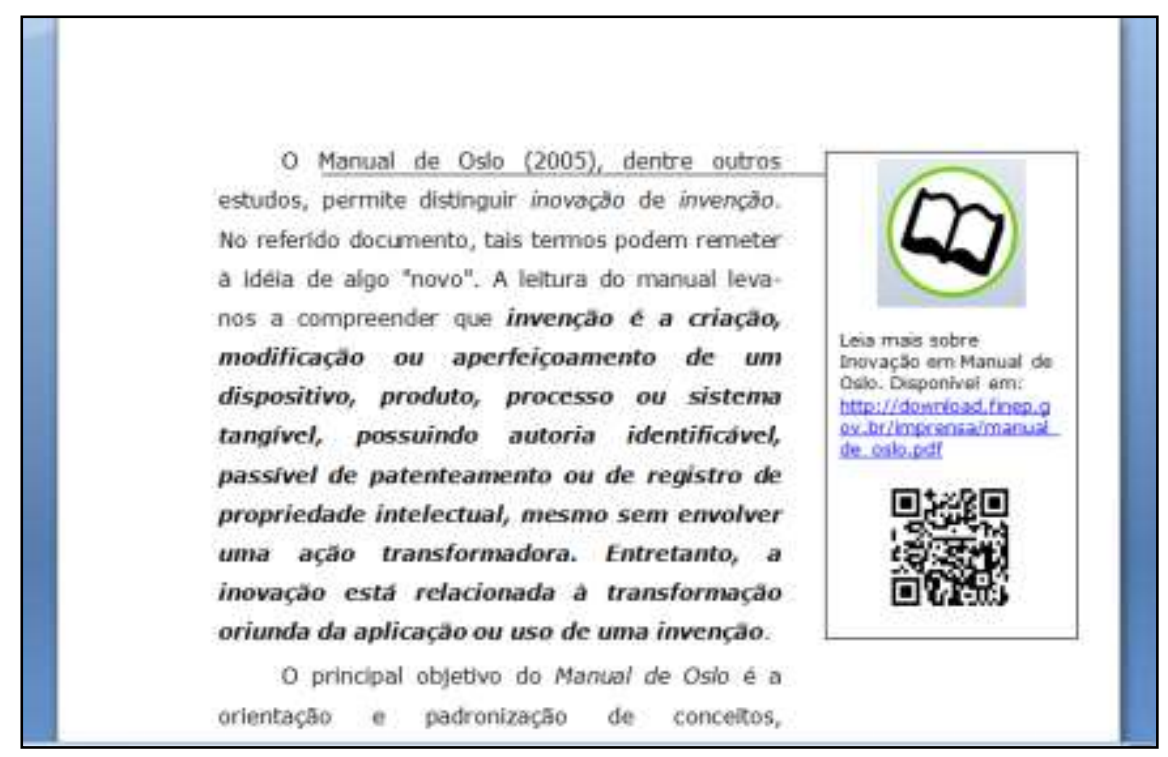

FIGURA 4 - Modelo de aplicação interativa no Caderno didático Fonte: Protótipo do Caderno didático

Desse modo, fomos trabalhando os conteúdos abordados no texto e verificando o melhor ícone, conforme figura 3, para representar a temática abordada a fim de conduzir o gestor a buscar diferentes caminhos para a aprendizagem.

Para representar a inteligência linguística, escolhemos dois tipos de ícones: um em forma de livro e um em forma de computador, com potencial para ativar as mentes disciplinada, sintetizadora e criadora. Já a inteligência lógico-matemática foi representada por meio do uso do ícone em forma de jogo de xadrez, podendo ativar as mentes disciplinada, sintetizadora e criadora. Para representar a inteligência musical, escolhemos o ícone em forma de fone de ouvido, definido por Zandomeneghi (2005) como escutando música. Esse ícone poderá ativar as mentes disciplinada e sintetizadora. 
A inteligência espacial, por sua vez, foi pensada por meio da utilização do ícone em forma de globo inserido duas vezes no caderno didático, com potencial para ativar as mentes disciplinada, sintetizadora e criadora. Para representar a inteligência corporal-cinestésica escolhemos o ícone denominado por Zandomeneghi (2005) como dramatização, podendo ativar as mentes disciplinada, sintetizadora e criadora. Quanto à inteligência intrapessoal, foi inserida por meio do ícone denominado por Zandomeneghi (2005) como espelho, com potencial para ativar as mentes disciplinada, sintetizadora, criadora e ética. Para representar a inteligência interpessoal, escolhemos o ícone denominado por Zandomeneghi (2005) como grupo de pessoas, podendo ativar, significativamente, a mente respeitosa.

Na produção da videoaula, elaboramos uma aula de trinta minutos que complementará o conteúdo abordado pelo caderno didático, compondo, dessa forma, o protótipo de material didático hipermídia. A videoaula corresponde ao vídeo de origem e foi construída a partir de um roteiro interativo para TVDI, conforme figura 5, elaborado pelo professor conteudista. $\mathrm{O}$ processo de criação desse roteiro foi baseado nos pressupostos da hipermídia e da não linearidade, que tem a premissa de enfatizar a criação de múltiplos caminhos, possibilitando a gravação de uma videoaula com estilo televisivo interativo em que o apresentador figura como mediador e estimulador das ações do espectador-aprendente.

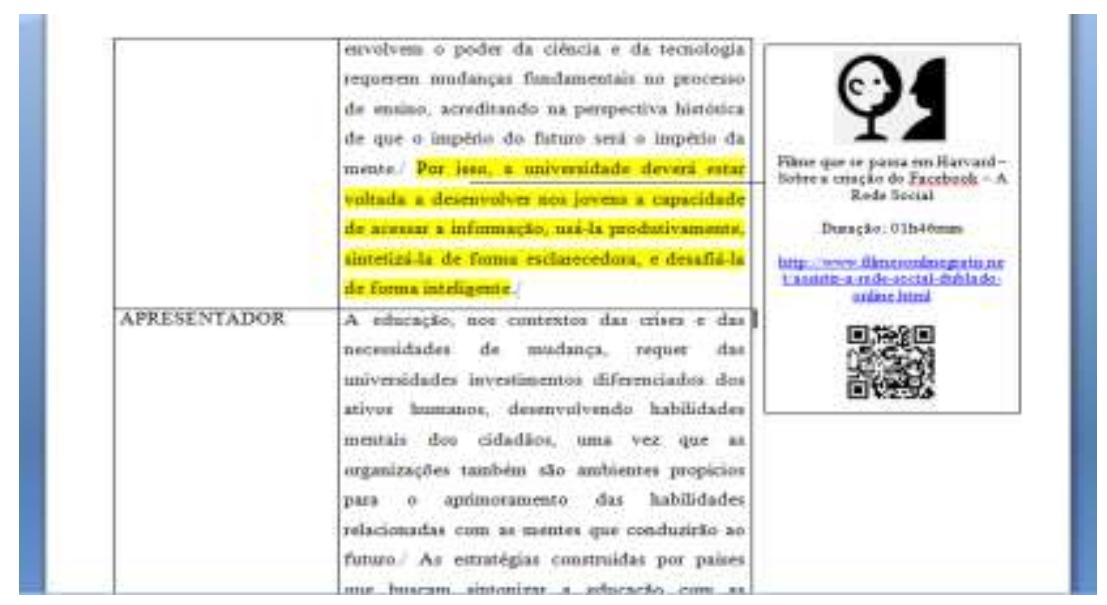

FIGURA 5 - Modelo de aplicação interativa no Roteiro Interativo para TVDI Fonte: Protótipo do Roteiro Interativo para TVDI

A gravação da videoaula foi realizada por uma equipe interdisciplinar composta por profissionais das áreas de ciência da computação, comunicação e de educação, tendo como âncora o próprio professor que elaborou o roteiro. Contou ainda com três professores entrevistados abordando a temática inovação no serviço público. Visualiza-se no quadro 1 a ficha técnica da videoaula. 
QUADRO 1 - Ficha técnica da videoaula Inovação na Gestão Universitária: o desafio das cinco mentes

\begin{tabular}{|l|l|}
\hline Titulo & Inovação na Gestão Universitária: o desafio das cinco mentes \\
\hline Tempo de Duração & 30min \\
\hline Estrutura curricular & Formação Gerencial \\
\hline Objetivo & $\begin{array}{l}\text { Apresentar ao aprendente respostas aos seguintes questionamentos: } \\
\text { o que é inovação? No contexto da globalização, como a perspectiva } \\
\text { da inovação se consolida como política organizacional? Como o } \\
\text { setor público pode lidar com processos de inovação significativos às } \\
\text { suas próprias demandas e serviços? Sabemos que a universidade } \\
\text { brasileira é o lócus mais importante de produção da inovação, mas } \\
\text { mesmo assim indagamos: é possível a inovação nos serviços que a } \\
\text { universidade oferece? Podemos considerar as Instituições de Ensino } \\
\text { Superior públicas como lugar da gestão inovadora? Como podemos } \\
\text { pensar a inovação a partir do desenvolvimento de capacidades } \\
\text { cognitivas cada vez mais competentes? }\end{array}$ \\
\hline Sinopse & $\begin{array}{l}\text { Discutir a inovação como estratégia de gestão no setor público a } \\
\text { partir de dois eixos fundamentais: a) a inovação como desafio dos } \\
\text { processos de gestão na universidade; e b) o processo de formação e } \\
\text { atuação de gestores a partir dos cinco tipos de mentes: a mente } \\
\text { disciplinada, a mente sintetizadora, a mente criadora, a mente } \\
\text { respeitosa e a mente ética./ }\end{array}$ \\
\hline Autor & Professor Dr. José Washington de Morais Medeiros \\
\hline
\end{tabular}

A interatividade construída para a videoaula foi realizada a partir do roteiro interativo para TDVI e da utilização da ferramenta MARKER.

Para representar a inteligência linguística, escolhemos o ícone em forma de computador, com potencial para ativar as mentes disciplinada, sintetizadora e criadora. A inteligência lógico-matemática foi pensada através do uso do ícone em forma de jogo de xadrez, utilizado três vezes na videoaula, podendo ativar as mentes disciplinada, sintetizadora e criadora. Para representar a inteligência musical escolhemos o ícone em forma de nota musical, que poderá ativar a mente disciplinada e sintetizadora. A inteligência espacial foi pensada por meio da utilização do ícone em forma de globo, com potencial para ativar as mentes disciplinada, sintetizadora e criadora. Para representar a inteligência intrapessoal foi utilizado o ícone denominado por Zandomeneghi (2005) como espelho, com potencial para ativar as mentes disciplinada, sintetizador, criadora e ética. A inteligência interpessoal foi pensada através do uso do ícone denominado por Zandomeneghi (2005) como grupo de pessoas, utilizado três vezes na videoaula, podendo ativar a mente respeitosa. 
Buscamos, ao elaborar o protótipo de material didático hipermídia, motivar o aprendente a ampliar seu conhecimento sobre o tema trabalhado mediante a utilização de suportes multimídia e linguagem hipermídia que possibilitem o hipertexto com a liberdade de escolha, de nexos, iniciativa de direções e rotas para o conhecimento. Essas potencialidades envolvem transformações sensórias, perceptivas e cognitivas que trazem novas possibilidades de sensibilidade corporal, física e mental.

\section{ANÁLISE DO PROTÓTIPO}

A análise do protótipo tratou da etapa em que o modelo e suas hipóteses foram confrontados com os dados empíricos, comparando suas soluções e previsões a partir do protótipo produzido. $\mathrm{Na}$ pesquisa, esse foi o instante de verificar se a relação entre a inteligência que se deseja ativar e o conteúdo inserido com o respectivo ícone estão coerentes, como também se as inteligências tornaram o conteúdo com potencial para ativar as cinco mentes como coloca Gardner (2007).

Além disso, o grau de aproximação dessa validação com as previsões iniciais determinaram a validação do modelo. Caso ele não atenda às necessidades que o geraram, o processo deve ser retomado com base na abstração, mudando-se ou ajustando-se hipóteses, variáveis e os demais aspectos que envolvem a fase de abstração. É possível, também, retornar à fase de experimentação, no sentido de buscar uma nova constatação sobre a possibilidade de construção do conteúdo interativo, conforme proposto pelo modelo.

Segundo autores como Bardin (2009) e Minayo (2000), a análise de conteúdo abrange as iniciativas de explicitação, sistematização e expressão do conteúdo de mensagens, com a finalidade de se efetuarem deduções lógicas e justificadas a respeito da origem dessas mensagens. Por ser utilizada em pesquisas empíricas, a análise de conteúdo não possui um modelo exato, porém, esses autores apresentam as etapas desse método:

a) A pré-análise: organização e sistematização das ideias, com a escolha dos documentos a ser analisados e a retomada dos objetivos iniciais da pesquisa;

b) A exploração do material: codificação do material de pesquisa;

c) Tratamento dos resultados obtidos e interpretação: os dados brutos tornam-se significativos e válidos para evidenciarem as informações coletadas e, então, o pesquisador realiza suas interpretações.

Na etapa de pré-análise, foi realizada a sistematização das ideias iniciais, de maneira a conduzir a um esquema preciso do desenvolvimento das operações sucessivas. Desse modo, com base no diagnóstico de dados empíricos sobre o processo atual de formação de gestores da UFRN, definimos as sete inteligências a ser utilizadas como aplicação interativa no material didático hipermídia composto por Caderno didático e videoaula. Dando continuidade, verificamos se os recursos interativos produzidos tinham potencial para acionar as cinco mentes para o futuro, definidas por Gardner (2007) como: disciplinada, 
sintetizadora, criadora, ética e respeitosa. Ao se confirmar essa hipótese, validamos o modelo conceitual para a construção do protótipo de material didático hipermídia com o uso da ferramenta MARKER.

A próxima etapa, a exploração do material, correspondeu à aplicação interativa, utilizando a ferramenta MARKER, com base no conteúdo abordado, que teve como tema a inovação organizacional especificamente voltada para o desenvolvimento de estratégias de gestão no setor público. Inserimos no material de origem - o caderno didático e a videoaula os ícones, conforme figura 3, com possibilidade para representar até sete inteligências múltiplas definidas (linguística, lógico-matemática, musical, espacial, corporal-cinestésica, intrapessoal e interpessoal), associados a conteúdos como imagem, vídeo, áudio, textos e mídias desacopladas, que permitirá ao aprendente estabelecer conexões com outros conteúdos que considere primordiais à aprendizagem.

Dessa forma, verificamos se os conteúdos dispostos através dos ícones apresentam consistência com o ícone, tornando-se um conteúdo para ativar a inteligência correspondente; ao mesmo tempo, nessa exploração, averiguamos se a interatividade produzida possui potencial para acionar as cinco mentes. No tratamento dos resultados, as inferências e interpretações foram feitas a partir da fundamentação teórica e dos pressupostos que conduziram a investigação.

Exemplificamos, abaixo, a análise interativa produzida para a videoaula à luz da inteligência lógico-matemática e das cinco mentes para o futuro, conforme segue:

\subsection{Vídeoaula}

\section{- A inteligência lógico-matemática}

Para ativar a inteligência lógico-matemática, foram utilizados três vezes o ícone representativo em forma de jogo de xadrez. Ao ser acionado pela primeira vez, apresenta como conteúdo o filme "Tempos modernos", com duração de uma hora e vinte e três minutos, o qual retrata o contexto da Revolução Industrial que transformou o trabalho em emprego. Assim, os trabalhadores passaram a trabalhar por salários, surgindo uma nova cultura. Com o surgimento das máquinas industriais, surgiram novos métodos de produção, que aumentaram a produtividade, causando desemprego. Desse modo, a excessiva oferta de mão de obra causou redução dos salários, com jornadas extensas e condições de trabalho arriscadas.

Ao ser acionado em sua segunda inserção, apresenta como conteúdo o tutorial com instruções para instalação e manuseio do jogo empresarial "Gestão organizacional", com duração de vinte e seis minutos, desenvolvido pela Universidade Federal Rural de Pernambuco (UFRPE), que proporciona ao gestor experienciar, por meio da simulação de cenários, dicas e estratégias de modelos de gestão sob a lógica de formular, implementar e 
controlar a estratégia da empresa, praticar as ferramentas e os modelos funcionais de gestão e desenvolver habilidades na tomada de decisão sob incerteza.

E o terceiro ícone, ao ser acionado, apresenta como conteúdo um vídeo com o desenho do "Bob Esponja", no episódio "Redação", com duração de onze minutos e dezesseis segundos, conforme retratado nas figuras 6 e 7. Essa aplicação interativa permite a comparação da mensagem retratada no desenho com fatores essenciais ao ambiente organizacional como: planejamento e definição de estratégias, foco nas pessoas e no ambiente e questões de administração do tempo.

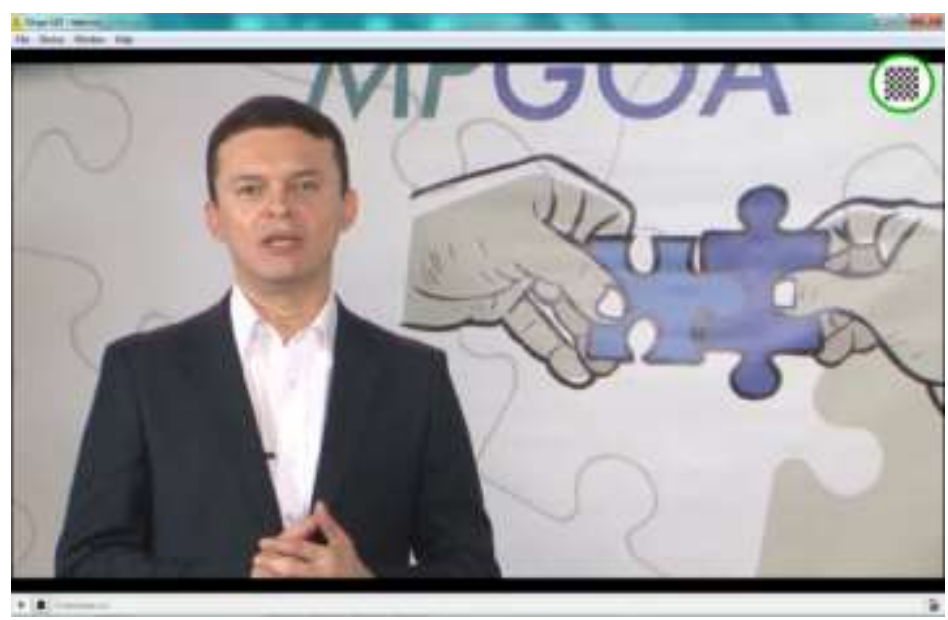

FIGURA 6 - Modelo de aplicação interativa na videoaula Fonte: Autoria própria

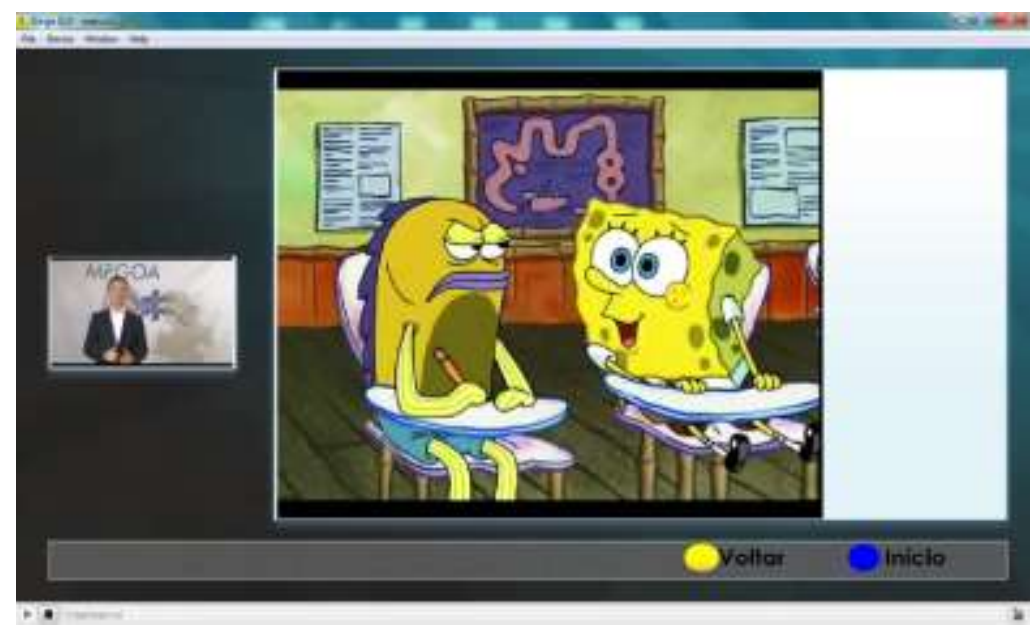

FIGURA 7 - Conteúdo acionado a partir do ícone da inteligência lógico-matemática Fonte: Autoria própria

As três mídias utilizadas, o filme, o jogo empresarial e o desenho, constituem importantes ferramentas no processo de aprendizagem do gestor e permitirão que ele possa analisar e interpretar, de acordo com o seu conhecimento, suas estratégias de gestão tomadas anteriormente. Isso facilita o funcionamento da inteligência, uma vez que a construção das 
novas estratégias dependerá de uma série de assimilações e acomodações dos conceitos durante o processo de tomada de decisão.

Com esse processo lógico de comparação, verificamos que o ícone apresenta consistência com o conteúdo abordado e poderá potencializar a inteligência lógicomatemática, de forma que, segundo Gardner (2000), permita a estimulação da capacidade de usar os conceitos de forma efetiva, manifestada na solução de problemas e no desenvolvimento do raciocínio dedutivo, com base em padrões e relacionamentos lógicos, ordem e sistematização, afirmações e proposições, e outras abstrações relacionadas, implicando na utilização do raciocínio abstrato e da organização lógica do pensamento.

Ao aprimorar a inteligência lógico-matemática, o gestor terá potencial para ativar as mentes disciplinada, sintetizadora e criadora, tendo em vista que, segundo Gardner (2000), essa forma de inteligência manifesta-se na facilidade para o cálculo, na sensibilidade para padrões, ordem e sistematização e na capacidade para reconhecer e resolver problemas. Dessa maneira, o gestor, ao ter contato com as diferentes formas de trabalhar a lógica, por meio da comparação de contextos originados pelo filme, bem como o contato com o recurso lúdico do jogo e do desenho para produzir conhecimento, terá a capacidade de associar diversos conceitos por meio da mente disciplinar, e ainda integrar e sintetizar conhecimentos acionando a mente sintetizadora e aplicar esse conhecimento resolvendo problemas com base na mente criadora.

\section{CONSIDERAÇÕES FINAIS}

Nesta pesquisa, os conteúdos interativos audiovisuais foram produzidos com vistas a acionar um conjunto de inteligências no aprendente. Assim, as descobertas desta pesquisa comprovaram os pressupostos levantados, demonstrando que as aplicações interativas produzidas para TVDI, ancoradas pela TIM, com o uso da ferramenta MARKER podem possibilitar aos gestores acionar suas múltiplas inteligências e buscar diferentes caminhos para a aprendizagem. A validação do modelo permitiu verificar que a interatividade proporcionada pelo material pode conduzir o aprendente a desenvolver potencialidades para acionar as mentes mais valorizadas no futuro.

Nossas análises apontam que as aplicações interativas produzidas podem possibilitar aos gestores entender o tema abordado na aula numa perspectiva de suas múltiplas potencialidades, uma vez que devem buscar diferentes caminhos para a aprendizagem por meio das conexões estabelecidas com outros conteúdos relacionados com o objetivo do caderno didático e da videoaula.

Partimos assim de um problema e, para resolvê-lo, passamos pelo diagnóstico de dados empíricos sobre o processo atual de formação da UFRN. Em seguida, navegamos por categorias, princípios e axiomas da teoria das inteligências múltiplas para traduzir uma forma de pensar que gerou o modelo conceitual necessário para fundamentar a produção do 
protótipo de material hipermídia que, aplicado na formação gerencial, viesse a ativar um conjunto de inteligências nos gestores, contribuindo, desse modo, para o possível desenvolvimento das mentes necessárias no intuito de que o gestor moderno busque respaldo para a sua atuação.

\section{REFERÊNCIAS}

BARDIN, Laurence. Análise de conteúdo. Lisboa: Edições 70, 2009.

BASSANEZI, Rodney Carlos. Ensino-aprendizagem com modelagem matemática. Editora Contexto, 2002.

BELLONI, Maria Luiza. Educação a distância. 3. ed. Campinas: Autores Associados, 2008.

BRENNAND, Edna Gusmão de Góes; LEMOS, Guido. TV digital interativa: reflexões, sistemas e padrões. São Paulo: Mackenzie, 2007.

GARDNER, Howard. As tecnologias da inteligência: o futuro do pensamento na era da informática. São Paulo: 34: Literatura, 1996.

GARDNER, Howard. Cinco mentes para o futuro. Porto Alegre: Artmed, 2007.

GARDNER, Howard. Estruturas da mente: a teoria das inteligências múltiplas. Tradução de Sandra Costa. 2. ed. Porto Alegre: Artmed Editora, 2000.

GARDNER, Howard. Inteligência: um conceito reformulado. Rio de Janeiro: Objetiva, 2001.

MINAYO, Maria Cecília de Souza. O desafio do conhecimento: pesquisa qualitativa em saúde. 7. ed. São Paulo: Hucitec, 2000.

NEDER, Maria Lucia Cavalli. O texto como base para a comunicação em EAD. In: MARTINS, Onilza (Org.). Curso de formação em educação a distância: educação e comunicação em educação a distância. Curitiba: UNIREDE, 2001, p. 96-117.

PAIM, Rosele Luchesi. Sistema hipermídia sobre câncer de mama com interface adaptativa usando redes neurais IAC e MLP. 2006. 160 p. Dissertação (Mestrado em Engenharia Elétrica) - Universidade Federal de Santa Catarina, Florianópolis, SC, 2006. Disponível em: < https://goo.gl/PEkp2B >. Acesso em: 18 mai. 2015.

PALAZZO, Luiz Antônio Moro. Modelos pró-ativos para hipermídia adaptativa. 2000. 114 p. Tese (Doutorado em Ciência da Computação) - Instituto de Informática, Universidade Federal do Rio Grande do Sul, Porto Alegre, RS, 2000. Disponível em: < http://goo.gl/DQxYmr >. Acesso em: 18 mai. 2015.

SOARES, Ismênia Mangueira. A teoria das inteligências múltiplas como suporte para autoria de vídeos interativos. 2014. 157 f. Tese (Doutorado em Educação) - Centro de Educação, Universidade Federal da Paraíba, João Pessoa, PB, 2014. Disponível em: <http://goo.gl/yovFvp >. Acesso em: 18 mai. 2015. 
SOARES, Ismênia Mangueira; BRENNAND, Edna Gusmão de Góes; WASHINGTON, Sttiwe; et al. Mídias digitais como potencializadoras de múltiplas inteligências. In: COLÓQUIO INTERNACIONAL DE EDUCAÇÃO COM TECNOLOGIAS, 1., 2013, Recife, PE. Anais eletrônicos... Recife, 2013. Disponível em: 〈http://goo.gl/H5ATO9>. Acesso em: 10 jul. 2014. ISSN 1984-1175.

ZANDOMENEGHI, Ana Lúcia Alexandre de Oliveira. Ícones representativos das inteligências múltiplas. 2005. 207 f. Tese (Doutorado em Engenharia de Produção) Universidade Federal de Santa Catarina, Florianópolis, SC, 2005. Disponível em: < https://goo.gl/miJFUO>. Acesso em: 18 mai. 2015.

Como citar este documento:

SANTOS, Raquel Alves; BRENNAND, Edna Gusmão de Góes; SOARES, Ismênia Mangueira. Aplicações interativas como potencializadoras de múltiplas inteligências. ETD - Educação Temática Digital, Campinas, SP, v. 18, n. 2, abr/.jun. 2016. ISSN 1676-2592. Disponível em: <http://periodicos.sbu.unicamp.br/ojs/index.php/etd/article/view/8635194>. Acesso em: 05 jul. 2016. doi:http://dx.doi.org/10.20396/etd.v18i2.8635194. 